\title{
AN ANALYSIS OF IN-SITU SYNTHESIZED AL 6061 ALLOY METAL MATRIX COMPOSITES: REVIEW
}

\author{
Sami ULLAH KHAN ${ }^{1,2, *}$, Ding WANWU ${ }^{1,2}$, Qudrat ULLAH KHAN ${ }^{3}$, \\ Shadab KHAN ${ }^{4}$, Abid $\mathrm{ALAM}^{5}$, Arif ULLAH ${ }^{6}$, Hanif ULLAH ${ }^{7}$ \\ ${ }^{1}$ State Key Laboratory of Advanced Processing and Recycling of Nonferrous Metals, \\ Lanzhou University of Technology, Lanzhou 730050, P.R. China. \\ ${ }^{2}$ School of Material Science and Engineering, Lanzhou University of Technology, \\ Lanzhou 730050, Gansu Province, P.R. China. \\ ${ }^{3}$ Greater Bay Area Institute of Precision Medicine (Guangzhou), Fudan University, \\ Nansha District, Guangzhou, Guangdong 511458, P.R. China. \\ ${ }^{4}$ Department of Physics, Abbottabad University of Science \& Technology, Captain Akaash \\ Rabbani Shaheed Road, Tehsil Havelian, District Abbottabad, Khyber Pakhtunkhwa, Pakistan. \\ ${ }^{5}$ The Key Laboratory of Magnetism and Magnetic Materials, Ministry of Education, \\ School of Physical Science and Technology, Lanzhou University, Lanzhou-730030, Gansu P.R. China. \\ ${ }^{6}$ Gansu International Scientific and Technological Cooperation Base of Water-Retention Chemical \\ Functional Materials, College of Chemistry and Chemical Engineering, Northwest \\ Normal University, Lanzhou, Gansu 730070, People's Republic of China. \\ ${ }^{7}$ Research Assistant in Advance Manufacturing Technology Lab, School of Mechanical Science and Engineering, \\ Huazhong University of Science and Technology, 1037 Luoyu Road, Wuhan 430074 Hubei Province P.R China.

\begin{abstract}
Many alloys and aluminum composites have been produced in recent years for improved material performance. Al 6061 is now an aluminum alloy with a wide range of uses owing to its excellent microstructure. For the manufacture of aluminum matrix composites (AMC), it is a wise option for the matrix. The in-situ process produces Al 6061 aluminum alloy matrix composites, according to this research. It investigates the mechanical properties of Al 6061 composites, modern in-situ fabrication, processing conditions, and multiple reinforcements employed. Numerous researches have shown that the latest in-situ process is commonly used and ideal for designing Al-6061 Alloy composites reinforcing $\mathrm{TiC}, \mathrm{TiB}_{2}, \mathrm{Al}_{2} \mathrm{O}_{3}, \mathrm{SiC}$, and other inorganic, biological elements, hybrid, and nanomaterials. A variety of researchers indicated that higher reinforcement material increased the composites' mechanical and tribological properties. Moreover, hybrid composites outperformed single-reinforcement composites in terms of material properties. Industrial and agricultural residues are also recorded to be used in hybrid composites. Scientific investigations should concentrate on in-situ processing and material characterization of Al 6061 nanocomposites, which have a lot of promise as exotic technologies.
\end{abstract}

Keywords: in-situ, fabrication techniques, metal matrix composites, reinforcements, microstructural properties, Al-6061 Alloy

\section{Introduction}

Because of their many favorable material properties, aluminum alloys are the most commonly used nonferrous metal in various applications [1]. As a result of the intensive research, several aluminum alloys have been developed to improve particular material properties [2]. Composites are multistage structures made up of reinforcement and matrices created to meet the growing need for visually appealing engineering materials. Composites have superb thermal properties and exceptional mechanical properties, such as higher strength, stiffness, crack 
durability and wear and corrosion resistance [3]. Composite materials have become more common in industrial applications due to their outstanding properties [4]. The form of matrix material contained in a composite determines its classification. Polymer matrix composites (PMCs), ceramic matrix composites (CMCs), and metal matrix composites are three of the most common forms (MMCs) [5]. Because of their numerous advantages over PMCs and CMCs, MMCs are the most commonly used composite in industrial applications. Metal can be used as the matrix material in MMCs $[6,7]$. It's the composite's continuous process, and it serves as a binding agent to keep the reinforcing in place. Aluminum matrix composites (AMCs) are made up of pure aluminum or an alloy, and they are progressively used in industrial applications due to their superior mechanical, structural, and tribological properties[8]. As a result, AMCs were developed using various aluminum alloys as a matrix and different reinforcing materials to achieve the desired properties [9]. Depending on their intended use, AMCs may be made in a variety of ways. Aluminum alloys have been the favored material for aviation parts manufacturing since the 1930s [10]. In the aerospace and transportation sectors, the Al 6XXX aluminum alloy series, silicon, and magnesium are the main alloying components, are gaining popularity $[11,12]$. This set of alloys has an impressive strength-to-weight ratio and better dimensional stability, machinability, and corrosion resistance. It is relatively cheap, making it a possible material for lightweight automotive [13]. Because of the ability to change the composite strength by proper heat treatment, Al-6061 Alloy is one of the most common alloys in the 6XXX range, and it is used as matrix material in a number of AMCs [14]. Because of their distinct features and superior quality compared to their base materials, composite materials developed with enhanced characteristics have gotten a lot of attention in a variety of fields, including aerospace, auto parts, armed services, and other industrial activities [15]. The tangible advantage realized through composite production is a combination of the most important properties of matrix and reinforcements. The combination produces high-strength materials while maintaining alloy ductility and density [16]. The ability to reinforce matrix materials with high-strength particles also aids in overcoming their drawbacks [17]. The attachment of reinforcement to an aluminum matrix increases the composite's tensile strength, compressive strength, impact strength, and hardness [18]. AMCs generally have higher wear resistance than unreinforced aluminum or aluminum alloys [19]. In the manufacture of AMCs, several materials are used as reinforcements. They come in various shapes and sizes, including flakes, hairs, small filaments, and regular filaments [20]. Particle reinforcements have stronger thermodynamic properties [21] than the other forms, allowing them to propagate equally in the matrix process [22]. AMCs can be made of micro or nano-sized ceramic, synthetic, and agricultural waste reinforcement particles [23]. While composites have been identified as a viable alternative to traditional materials, there are still some challenges to overcome in composites technology development. The main aim of composite manufacturing is to enhance material properties, which is determined by a series of aspects like fabrication path, operating conditions, constituent materials, and structure. For obtaining the targeted properties, appropriate materials and fabrication methods must be chosen, as well as the best operating conditions. MMCs have been produced using a variety of processing processes, including liquid-state and solid-state techniques [24]. The in-situ method is the most commonly used industrial fabrication method [25] because of its special characteristics. The process's ease of use and adaptability made it a cost-effective tool for large-scale fabrication. Without destroying the reinforcement particles, complex profiled MMCs can be rendered in-situ [26]. While fabricating composites using the in-situ process, careful attention should be paid to ensuring a consistent distribution of reinforcing materials. Of the aluminum 6XXX alloy series, Al-6061 Alloy is the most flexible and Al-6061 Alloy composites are mainly manufactured insitu. To the best of the authors' understanding, there is no systematic analysis on Al-6061 Alloy in-situ composites despite the fact that several researchers have reviewed various Al-6061 Alloy composites and their fabrication. The paper's main goal is to go through the different types of MMCs that can be made in-situ using Al-6061 Alloy as the matrix material. The authors want to 
learn about how different reinforcements impact the Al-6061 Alloy matrix and whether the insitu process is feasible for these materials.

\section{Al-6061 Alloy (AA)}

Various types of aluminum alloys are currently available on the market, each with its own set of benefits and uses. Such an article concentrates on heat-curable Al-6061 Alloy (aluminum alloys) that can be significantly hardened and used in various applications where durability, machinability, and corrosion resistance are needed [27]. Table 1 shows the composition of the Al-6061 Alloy [28].

Table 1. Composition of Al-6061 Alloys

\begin{tabular}{cccccc}
\hline Element & Aluminum & Magnesium & Silicon & Ferrum & Copper \\
\hline Weight $\%$ & 97.2 & 1 & 0.6 & 0.40 & 0.275 \\
Element & Chromium & Zinc & Titanium & Manganese & \\
Weight $\%$ & 0.195 & 0.125 & 0.125 & 0.080 & \\
\hline
\end{tabular}

Tensile strength is $117 \mathrm{MPa}$,[29] hardness is $31 \mathrm{HRB}$, and modulus of elasticity is $75 \mathrm{MPa}$ in the base alloy. Al-6061 Alloy is primarily utilized in the aerospace and automobile sectors for lightweight components. A wide range of reinforcements, such as TiC, SiC, TiB2, A12O3, B4C, and others, have been used to design the metal matrix composite (MMC) using the Al-6061 alloy matrix. With the Al-6061 Alloy matrix, many nanocomposites have recently been developed on a higher level [30].

\section{Metal matrix composites (MMCs):}

MMCs have been made using several processes over the last period. The type of design phase used directly impacts the physical behavior and manufacturing cost of the composite [31]. These deposition techniques can be classified as solid-state or liquid-state processing depending on the condition of the metal matrix during primary process treatment [32]. Other semi-solid matrix techniques, such as stir casting design, spray deposition[33], rheocasting, and compo casting, are less common than solid- or liquid-state techniques [33]. The attachment of a matrix with reinforcements happens in solid-state fabrication due to reciprocal contact between them at higher temperatures and pressures. The scattering of reinforcements in the liquid matrix is accompanied by solidification, either by penetration or casting methods [34]. In comparison to solid-state systems, these methods are less expensive. Since it is more expensive than other production methods, in-situ processing is the most common and widely used technique in liquidstate processing [35, 36]. It also produces a more uniform reinforcement distribution in the matrix, and improved wettability aiming to lessen the porous quantity [37]. As compared to solid-state methods, these methods are less expensive. Since it is less expensive than other production methods, the in-situ approach is the most common and commercially used methodology in liquidstate processing. It also provides relatively uniform reinforcement dispersion in the matrix, improved wettability, and decreased porosity [38].

\section{In-situ technology}

The exothermic reaction between the compound parts is passed through ceramic particles in the "in-situ" process[39]. However, according to sources, much research has gone into "insitu" ceramic particle forming techniques, including hot reaction pressing, combustion reaction, and direct metal oxidation. Aluminum has a high reduction potential and can minimize many oxides, including $\mathrm{TiO} 2, \mathrm{ZrO} 2, \mathrm{CuO}, \mathrm{ZnO}$, and others [40]. As a result, "in-situ" particle training 
in the aluminum matrix is expected to be a successful manufacturing technique [41]. MMC has also attracted a lot of interest[42]. The interaction between the matrix and the reinforcement generally generates consistent and impurity-free products in the in-situ processing path [41]. The particles may also prevent oxidation of the molten atmosphere. A strong connection between the in-situ particles and the metal matrix is required for payload transfer in nanocomposites. Additionally, the particle size is finer and more evenly dispersed throughout the matrix with insitu molding reinforcement. It offers better mechanical characteristics than previously produced ex-situ composite materials [43]. For a variety of reasons, in situ composites are becoming increasingly popular. Internal chemical reactions among various elements during compounding manufacturing are usually used to reinforce the particles "in situ" [44]. For some reason, in situ composites are becoming more common. Second, endogenously synthesized particles are thermodynamically stable, with no surface oxidation or contamination, resulting in increased wettability and matrix bonding. Second, the particles in situ are smaller than those seen in traditional routines [45]. During solidification, fine in situ particles refine the grain shape, resulting in improved mechanical properties [46]. The schematic diagram of in-situ technique is shown in the (Fig. 1).

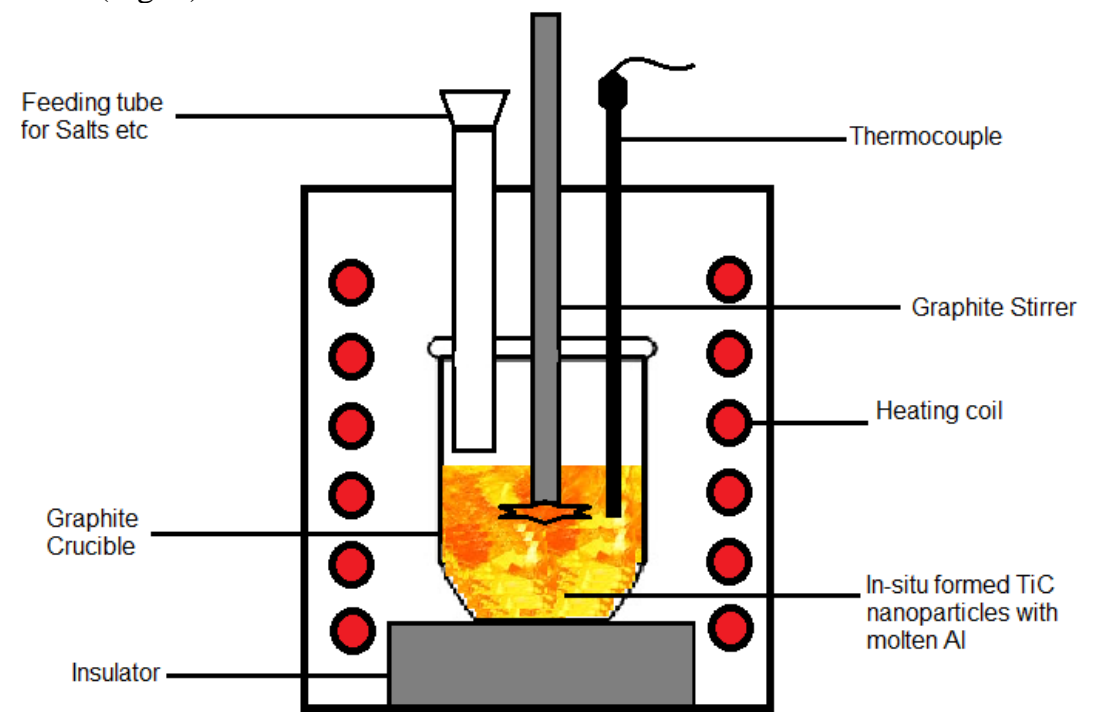

Fig. 1. Schematic diagram of in-situ fabrication

\section{Factor affecting mechanical properties:}

Several in-situ process parameters have a significant effect on AMC characteristics. Process variables, such as melting temperature, reinforced particle ratio, and size. However, they are found to have the greatest effect. Those parameters can be quickly changed in the process, saving time and money. As a result, method variable selection is essential.

By having a high melting temperature, the melt's wettability can be improved. High temperature, on the other hand, isn't necessarily preferable because it reduces melt viscosity. A low melt temperature favors particle agglomeration. As a result, for better properties, an excellent intermediate temperature value is preferred.

The size of the reinforcement has a significant impact on the strength of the content fabricated in-situ. Smaller reinforcing size composites also have stronger mechanical properties. Al-10Sb cast aluminum alloy-SiC composites are fabricated by Yehia M. Youssef et al. [47]. The $\mathrm{SiC}$ particle sizes used in the process were 115,225 , and $350 \mu \mathrm{m}$, with $3 \%, 5 \%$, and $9 \%$ weight fractions of $\mathrm{SiC}$ chosen for matrix reinforcement. Material characterization showed that the 
composite with the finest reinforcement particles (115 $\mu \mathrm{m}$ sizes) and nine wt\% SiC enhanced mechanical properties the most.

Under different situations, composite structures have superior physical properties and matrixes [48]. W. Hu et al. stated that a $40 \mathrm{wt} . \% \mathrm{TiC}$ reinforced composite material passes the ignition composite hardness throughout processing with a hardness of $55 \mathrm{HRC}$ [49]. F. Akhtar and B.H. Lee with colleagues, According to F. Akhtar TiB2 and TiC (30, 55, and 70 wt. \%) reinforced composite materials have a hardness of 75, 88, and 92HRA [50, 51]. Ferro-titanium and carbon black powder reinforced plastic material with in-situ TiC particles (N50 wt\%) The composite's optimum hardness was 83.2 HRA owing to a combination of in-situ synthesis and spark plasma sintering.

\section{Fabrication and design of Al-6061 MMC using in situ technology}

Powder metallurgy, the most popular solid-state processing method, manufactured Al6061 Alloy-B4C composites by H. Karakoç et al. [52]. Weight fractions of B4C of 5\%, 10\%, $15 \%$, and $20 \%$ were added to the MMC to reinforce it. The composite provided high relative density, hardness, and tensile strength due to the matrix structure's constant reinforcement particle distribution, as shown in (Fig. 2), indicating the microstructure surface under the scanning electron microscope.

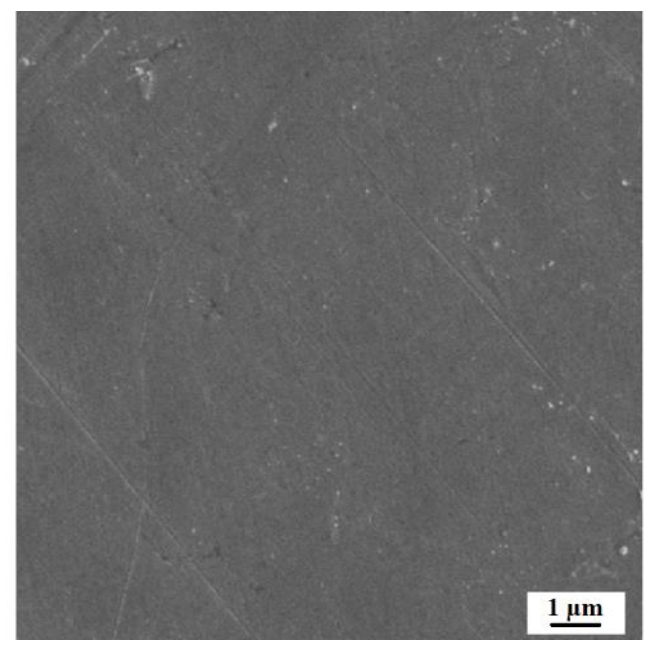

Fig. 2. SEM of Aluminum 6061 Alloy

M. Dhanashekar et al. employed powder metallurgy to construct an Al-6061 Alloy/SiC composite and studied its material properties [53]. According to a microstructural analysis, the particles were spread evenly, and the matrix and reinforcements had a deep connection. The composites' hardness, density, and stress power expanded as the $\mathrm{SiC}$ reinforcement weight concentration increased. The study implemented Al-6061 Alloy composites with a variety of reinforcements. Still, the bulk of the composites was made using the in-situ technique, the most popular liquid-state manufacturing method[39]. The method uses a traditional metal processing pathway, which lowers manufacturing costs. The ability to design large-scale composites adds to the appeal of this form of manufacturing. The reinforcement distribution in the matrix material should be uniform to accomplish the optimal MMC features. As a result, by carefully monitoring the operating factors and reinforcement weight fraction, Al-6061 Alloy composites with improved properties can be made. 
Scientists also produced a variety of Al-6061 Alloy composites with both organic and inorganic nanoparticles. The main objective of the distributed process is to properly attach the matrix to improve the properties of the basic ingredients. In particular, the reinforcement weight proportion in the composite varies from 5\% to 30\% of the Al-6061 Alloy weight. Numerous forms of reinforcements are combined and used as hybrid reinforcement in composite manufacturing, enhancing the properties even more [54]. Nano Al-6061 Alloy composites, which use nano-sized particles as reinforcements, are also gaining prominence amongst investigators.

This study focused on the various types of reinforcements used in the Al-6061 Alloy composites are discussed in detail. Throughout this portion, studies on Al-6061 Alloy composites fabricated in-situ are categorized according to the reinforcements used: Aluminum alloy 6061TiC composites, Composites Al-6061 Alloy-B4C, Aluminum alloy 6061-Al2O3 composites, Aluminum alloy 6061-Hybrid composites, Aluminum alloy 6061-Nano composites.

\section{Al-6061 Alloy-TiC}

Titanium carbide (TiC)-reinforced composites have outstanding adhesion properties, especially with aluminum, and have been recognized as a viable and attractive reinforcement for improving mechanical properties such as microhardness, wear resistance, and strength properties $[10,51]$. TiC particulates are also recognized as a viable reinforcement in AMCs [51]. Al-6061 Alloy-TiC particulate-reinforced composite was manufactured using an upgraded in-situ process by S.Rajesh, et al. [55]. Magnesium was required to enhance wetting in this process. Argon gas was being used to keep molten matrix content from interacting with the environment. The researchers created deformity composites with differing fiber reinforcement. As the amount of $\mathrm{TiC}$ was expanded, a significant rise in the material's specific strength was found due to TiC's resistance to plastic deformation [55]. The wear resistance of the AMC was also increased after a wear study using a pin on the disc device [56]. An AA 6063 alloy-TiC composite with good dispersion of $\mathrm{TiC}$ was also successfully developed using in-situ. It followed a similar pattern, improving the composite's density, hardness, and tensile strength. The raw powder of Titanium Carbide (TiC) with Aluminum-6061 Alloy were utilized as shown in the SEM image (Fig. 3) [57] which revealed the morphology of the reinforcing particulate. It shows that the particulate is composed of sharp corners with angular morphology.

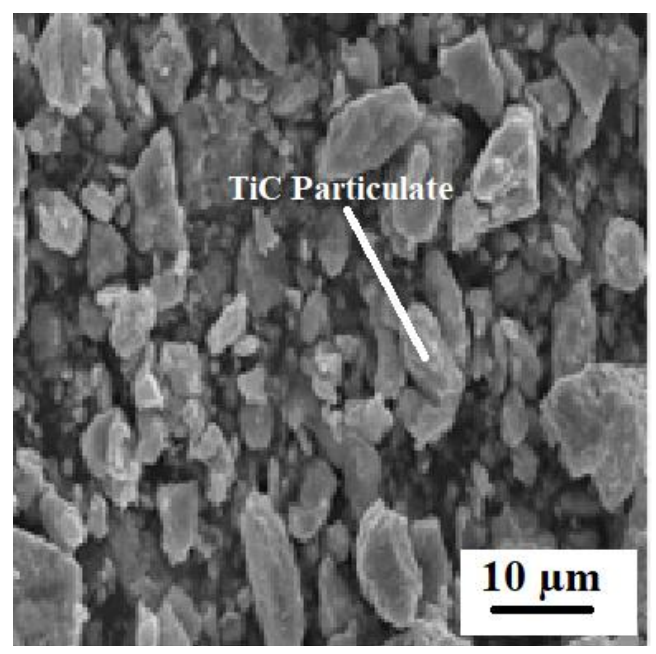

Fig. 3. SEM of TiC Raw Powder 


\section{Al-6061 Alloy-B4C}

Boron carbide (B4C) is a dark material with a shiny sparkle, one of the toughest ceramic products on the planet[58]. It's a common reinforcing material because of its high thermal and chemical stability[59]. In contrast to $\mathrm{Al} 2 \mathrm{O} 3$ and $\mathrm{SiC}$, it has a lower density of $2.52 \mathrm{~g} / \mathrm{cm} 3$ and a higher hardness (HV) of $30 \mathrm{GPa}$. It's used in the production of combat vehicles and body armor. As a result, B4C-reinforced AMCs made using the low-cost in-situ process have become more appealing [60]. Karabulut (Karabulut) et al. successfully designed Al-6061 Alloy-B4C composites with different reinforcement weight fractions (\%age) 5, 10, 15, and 20 [52]. The B4C particles in the composite were spread uniformly, according to the researchers. K2TiF6 flux was applied to improve the wettability of B4C particles with aluminum melt [59]. The flux reaction on the melted surface produced heat in the region near the interface, and the local elevation of temperature improved particle absorption into the melt and improved attachment. The uniform distribution of reinforcements was achieved by effective boiling in-situ and the use of appropriate control factors. The weight percentage of B4C particles improved the stiffness and tensile strength of the composites [61]. B. Ravi et al. designed composites with 5wt\% and 10wt $\%$ B4C specimens and discovered that particle dispersion occurred uniformly in the Al-6061 alloy matrix due to efficient mixing and suitable processing parameters [62]. During solidification, B4C particles triggered an increase in nucleation sites, reducing the grain size. The appearance of strong reinforcing particles on the surface increased hardness and helped to prevent plastic deformation. The load was successfully moved and transmitted from the matrix to the reinforcement, and the composite's UTS increased as a result of enhanced interfacial bonding between the matrix and reinforcement.

The application of coarse ceramic particulates on a ductile Al-6061 Alloy matrix resulted in a significant change. B. Manjunatha et al. demonstrated that the extrusion process can be performed after the Al-6061 Alloy-B4C composite has been manufactured [63]. The extrusion method helped to increase particle distribution, minimize particle size, and remove boundary effects. Heat treatment is another method for upgrading mechanical properties. The process can also generate Al-6061 Alloy-B4C composites with a much higher B4C content of up to $31 \%$ of the mass ratio.

\section{Al-6061 Alloy- $\mathrm{Al}_{2} \mathrm{O}_{3}$}

Aluminum oxide (A12O3) is the most widely used reinforcing material for AMCs, second only to silicon carbide because it has outstanding interfacial compatibility [64]. Al2O3 is a rigid ceramic with a low coefficient thermal expansion and a modest density $(3.97 \mathrm{~g} / \mathrm{cm} 3)$ [65]. The composites that result from display similar findings to those mentioned in the previous pages. Bhaskar Chandra Kandpal and co-authors used the in-situ technique to build effective Al-6061 Alloy/A12O3 composites [66]. Al2O3 was used to strengthen the Al-6061 Alloy in percentages of $5 \%, 10 \%, 15 \%$, and $20 \%$. SEM microstructures showed a highly uniform dispersion of nanoparticles.

As the weight percentage of reinforcement rose from $5 \%$ to $20 \%$, the physical characteristic showed that the strength and stiffness of the steel enhanced.

As we can observe Fig. 4. demonstrate the differences in ultimate tensile strength and Vickers hardness values obtained for various $\mathrm{Al} 2 \mathrm{O} 3$ weight percentages. The tensile and hardness tests showed that the UTS and hardness value increases as the weight fraction increases. The material's properties were enhanced by the addition of strong ceramic reinforcement particulates. The sum of reinforcement material was found to have a close interaction with the physical behavior of the AMCs [66]. 


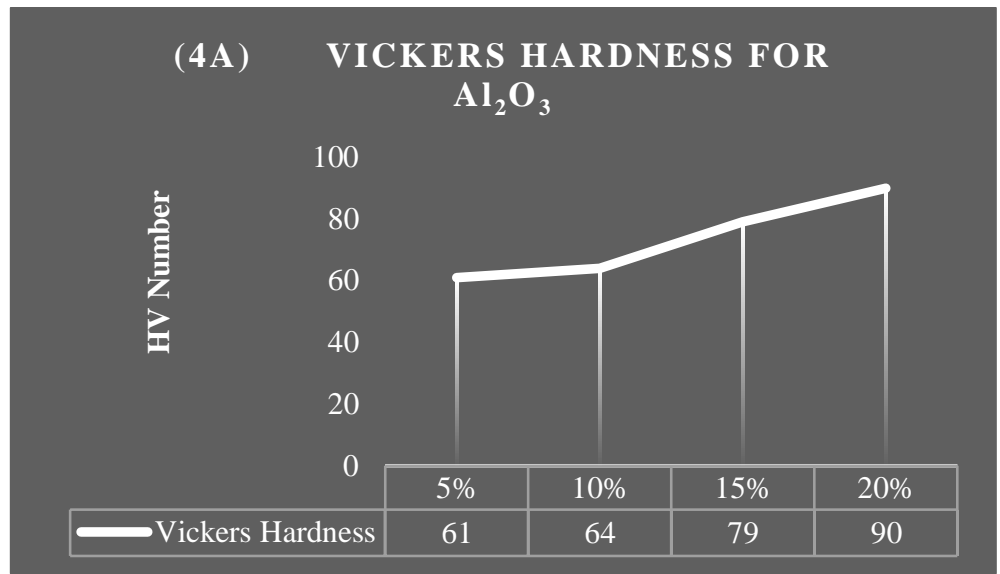

a)

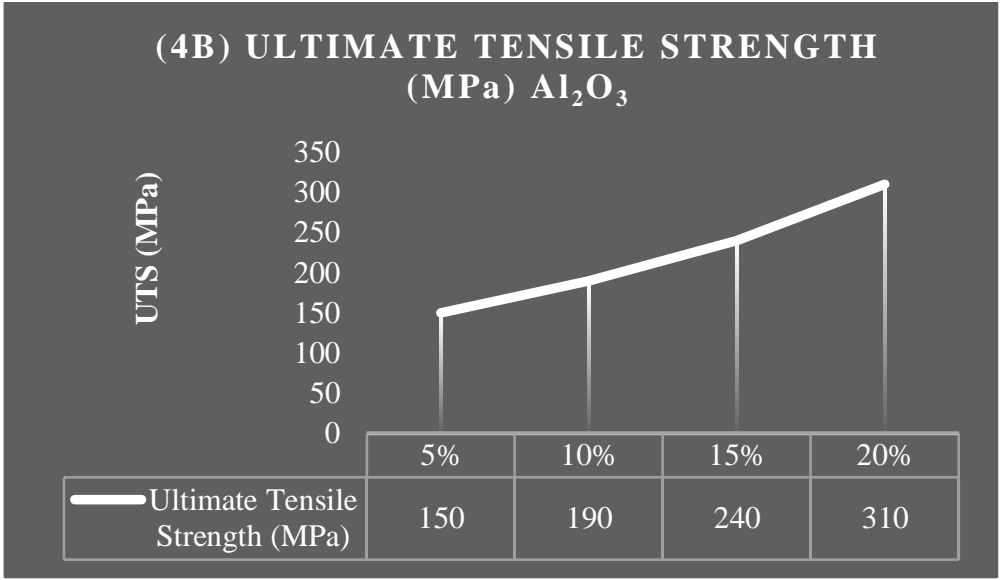

b)

Fig. 4. The variation of the mechanical properties of $\mathrm{Al}-6061$ Alloy- $\mathrm{Al}_{2} \mathrm{O}_{3}$ composite with increasing concentration of $\mathrm{Al}_{2} \mathrm{O}_{3}$ : a) Vickers hardness (HV); b) ultimate tensile strength-UTS (MPa)

\section{Al-6061 Alloy- Hybrid Composites}

Hybrid composites are artificial composite structures that use several types of reinforcement and may be either organic or inorganic [67]. Due to the use of secondary reinforcements in the matrix, these composites are designed to obtain outstanding properties. Handcrafted aluminum hybrid materials had excellent mechanical properties and thermal expansion coefficients [68]. The in-situ approach is widely used in the development of aluminumbased polymers [69]. The quantity and form of constituent materials in hybrid composites can be technically optimized to change material characteristics [70]. Consequently, reinforcements can only be added up to a minimum weight fraction; otherwise, they are useless. It is thought to be attributed to higher reinforcement content causing increased porosity and accumulation and the maximum weight percentage of reinforcement varying between composites [71]. In-situ methods are also used to create hybrid aluminum nanocomposites. The physical, structural properties and tribological properties of composites are improved by using the right reinforcements in the right amounts [72]. 


\section{Al-6061 Alloy-Matrix Nano Composites}

In AMCs, micro-level reinforcements are often used. Metal matrix nanocomposites are made possible by technological advancements in Nanosciences, and the resulting composites are referred to as metal matrix nanocomposites (MMNCs). In MMNCs, reinforcement is measured in nanometers $(109 \mathrm{~m})$. The key reasons for the increase in the properties of MMNCs are factors such as uniform dispersion, finer particle size, hardening process, inter-particle separation, and high-temperature thermal stability[73] [74]. Nano-sized particle-reinforced MMNCs outperform nanomaterial-reinforced MMCs in terms of strength, ductility, and wear resistance. Consequently, the former is the safer material option in terms of material properties, with possible uses in a wide variety of industries [75]. Researchers claim that combining nano-sized reinforcement particles with an aluminum alloy matrix improves the base material's mechanical, tribological, thermal, and interfacial capabilities. Sozhamannan G. et al. investigated the tribological activity of Al-6061 Alloy/nano TiC/graphite hybrid composites. TiC (3 wt\%) and homogeneous spreading of graphite reinforcing particles in the matrix (10 wt percent) [76]. The inclusion of reinforcements in the matrix restricted plastic deformation during the wear process, and the rate of wear was found to be $4.7 \%$ lower than that of the base alloy. During the wear test, the composite substantially decreased weight, which was 23.33 cents cheaper than the Al-6061 Alloy unreinforced. Al-6061 Alloy nanocomposites with $1 \mathrm{wt} \%$ and $2 \mathrm{wt} \%$ nano-silver (Ag) were made in situ [77]. When compared to conventional aluminum alloys, they had superior mechanical properties and wear resistance. The nanocomposites had a fine-grained microstructure, realistic silver nanoparticle distribution, and low porosity. The properties of nanocomposite improved as the mass fraction of nano-Ag particles increased, including hardness, stiffness, tensile, and compressive power. When reinforcement was increased from 0 to $2 \mathrm{wt}$. \%, the hardness value increased from 92 to 98 BHN. Wear tolerance and performance were increased, as were tribological properties [78].

\section{Conclusions}

The manufacture of Al-6061 Alloy metal matrix composites has been addressed in this study. The processing of Al-6061 Alloy metal matrix composites using an in-situ method was discussed in this study. Among the numerous fabrication techniques, in-situ has been described as the most outlay and widely used. As a result of the articles, the following conclusion has been reached:

- The ratio of the reinforcement particles had significant effects on the quality of the Al6061 alloy composites. The mechanical and tribological properties of the material could be improved by increasing the nanoparticles distribution of reinforcement. Placing reinforcement over a specific location may result in pores that agglomerate, degrading the microstructure. Al-6061 Alloy is a well-known aluminum alloy with a wide variety of applications. By strengthening various organic and inorganic materials in-situ, a variety of Al-6061 Alloy composites were created. In terms of characteristics, the composites made outperformed the parent alloy.

- It has been discovered that adding reinforcing to a liquid composite helps it solidify and refine the grain structure. The in-situ technique was used to build hybrid Al-6061 Alloy composites with excellent microstructural properties. Composite's mechanical, tribological, and corrosion properties were enhanced by using the right reinforcements in the right places. In-situ design of nanocomposites is possible as well. In this region, only a few studies have been conducted.

- Scientific investigations should concentrate on the efficient manufacturing of Metal Matrix Nanocomposites using in-situ processes. Investigators became capable of 
producing cost-efficient and necessary composite materials by successfully using waste materials, including quarry dust, thereby leading to conservation. Pores, clusters, and agglomeration were observed to be reduced while in-situ. It will result in a more uniform distribution of reinforcement particulates, boosting physical behavior and microstructural qualities.

\section{Acknowledgments}

We appreciate the technical help provided by Lanzhou University Technology's School of Material Science and Engineering in Lanzhou, Gansu Province, China.

\section{References}

[1] John, V., Non-ferrous Metals and Alloys, Introduction to Engineering Materials, Palgrave Macmillan UK, London. 1992, pp. 195-220.

[2] Stojanovic, B., M. Bukvic, and Epler. I, Application of aluminum and aluminum alloys in engineering, Applied Engineering Letter, 2018, 3(2), pp. 52-62.

[3] Rajak, D.K., et al., Recent progress of reinforcement materials, A comprehensive overview of composite materials. Journal of Material Research and Technology, 2019, 8(6), pp. 6354-6374.

[4] Abdudeen, A., et al. Evaluation of Characteristics of A390-SiC p Squeeze Cast and Gravity Cast Composites. in 2020 Advances in Science and Engineering Technology International Conferences (ASET). 2019. Institute of Electrical and Electronics Engineers.

[5] Daniel, I.M., et al., Engineering mechanics of composite materials. Vol. 1994. 2006, Oxford university press New York.

[6] Sharma, A.K., et al., A study of advancement in application opportunities of aluminum metal matrix composites. Materials Today, Proceedings 2020, 26, pp. 2419-2424.

[7] Sharma, D.K., D. Mahant, and G.J.M.T.P. Upadhyay, Manufacturing of metal matrix composites, A state of review. Materials Today, Proceedings, 2020, 26, pp. 506-519.

[8] Moghadam, A.D., et al., Mechanical and tribological properties of self-lubricating metal matrix nanocomposites reinforced by carbon nanotubes (CNTs) and graphene-a review. Composites Part B, Engineering, 2015, 77, pp. 402-420.

[9] Kumar, G.B.V., C.S.P. Rao, and N. Selvaraj, Mechanical and Tribological Behavior of Particulate Reinforced Aluminum Metal Matrix Composites "C a review, Journal of Minerals and Materials Characterization and Engineering, 2011, 10 (01), p. 33.

[10] Pandey, U., et al., Study of fabrication, testing and characterization of Al/TiC metal matrix composites through different processing techniques. Materials Today, Proceedings, 2018, 5(2), pp. 4106-4117.

[11] Benedyk, J., Aluminum alloys for lightweight automotive structures, in Materials, design and manufacturing for lightweight vehicles. Woodhead Publishing, 2010, pp. 79-113.

[12] Alam, T. and A.H. Ansari, Review on Aluminium and Its Alloys for automotive applications. International Journal of Advance Technology in Engineering Science, 2017, 5, pp. 278294.

[13] Mukhopadhyay, P., Journal of International Scholarly Research Network, Alloy designation, processing, and use of AA6XXX series aluminium alloys. 2012.

[14] Ozturk, F., et al., Influence of aging treatment on mechanical properties of 6061 aluminum alloy. Materials \& Design, 2010, 31(2), pp. 972-975. 
[15] Mavhungu, S., et al., Aluminum matrix composites for industrial use, advances and trends. Procedia Manufacturing, 2017, 7, pp. 178-182.

[16] Huang, Y., Z. Chen, and Z. Zheng, A conventional thermo-mechanical process of $\mathrm{Al}-\mathrm{Cu}-$ $\mathrm{Mg}$ alloy for increasing ductility while maintaining high strength. Journal of Scripta Materialia, 2011, 64(5), pp. 382-385.

[17] Joel, J. and M.A. Xavior, Aluminium alloy composites and its machinability studies; a review, Materials Today, Proceedings, 2018, 5(5), pp. 13556-13562.

[18] Akbari, M.K., H. Baharvandi, and O. Mirzaee, Nano-sized aluminum oxide reinforced commercial casting A356 alloy matrix, Evaluation of hardness, wear resistance and compressive strength focusing on particle distribution in aluminum matrix, Journal of Composites Part. B Engineering, 2013, 52, pp. 262-268.

[19] Awasthi, A., et al., Mechanical Characterization of hybrid aluminium composite-a review, Materials Today, Proceedings, 2018, 5(14), pp. 27840-27844.

[20] Chawla, K.K., Composite materials, science and engineering, Springer Science \& Business Media, 2012.

[21] Rahimian, M., et al., The effect of particle size, sintering temperature and sintering time on the properties of Al-Al2O3 composites, made by powder metallurgy, Journal of Material Processing Technology, 2009, 209(14), pp. 5387-5393.

[22] Tjong, S., Z. Ma, Microstructural and mechanical characteristics of in-situ metal matrix composites. 2000, Journal of Material Science and Engineering, R. Reports, 29(3-4), pp. 49-113.

[23] Srivyas, P.D. and M. Charoo, Role of reinforcements on the mechanical and tribological behavior of aluminum metal matrix composites-a review. 2018, Journal of Materials Today, Proceedings 5(9), pp. 20041-20053.

[24] Ward-Close, C., et al., Advances in the fabrication of titanium metal matrix composite. Material Science \& Engineering, 1999, A 263(2), pp. 314-318.

[25] Mandal, A., et al., Ageing behaviour of A356 alloy reinforced with in-situ formed TiB2 particles. 2008, 489(1-2), pp. 220-226.

[26] Lu, L., M. Lai, and F.J.A.M. Chen, Al-4 wt\% Cu composite reinforced with in-situ TiB2 particles. Material Science \& Engineering, 1997, A 45(10), pp. 4297-4309.

[27] Troeger, L., E. Starke Jr, Microstructural and mechanical characterization of a superplastic 6xxx aluminum alloy, Material Science \& Engineering, 2000, A 277(1-2), pp. 102-113.

[28] Dorward, R., C. Bouvier, A rationalization of factors affecting strength, ductility and toughness of AA6061-type Al-Mg-Si-(Cu) alloys, Material Science \& Engineering, 1998, A 254(1-2), pp. 33-44.

[29] Singh, H., et al., A comprehensive review of aluminum matrix composites reinforcement and fabrication methodologies, Functional Composites and Structures, 2021.

[30] Deng, K., et al., Effect of particle size on microstructure and mechanical properties of SiCp/AZ91 magnesium matrix composite, Material Science \& Engineering, 2012, A 543, pp. 158-163.

[31] Calado, E.A., M. Leite, and A.J. Silva, Selecting composite materials considering cost and environmental impact in the early phases of aircraft structure design, Journal of Cleaner Production, 2018, 186, pp. 113-122.

[32] Sahoo, B.P. and D. Das, Critical review on liquid state processing of aluminium based metal matrix nano-composites, Journal of Material Today Proceeding, 2019, 19, pp. 493-500.

[33] Tian, S., et al., Effect of surface roughness on tribological properties of TiB2/Al composites, Materials \& Design, 2014, 53, pp. 129-136. 
[34] Garg, P., et al., Advance research progresses in aluminium matrix composites, manufacturing \& applications, Journal of Material Research and Technology, 2019, 8(5), pp. 4924-4939.

[35] Li, H., et al., Synthesis, microstructure, and mechanical properties of in situ TiB2/Al-4.5 Cu composites, Science and Engineering of Composite Materials, 2018, 25(3), p. 453-462.

[36] Premkumar, M., M. Chu, Al TiC particulate composite produced by a liquid state in situ process, Material Science \& Engineering, 1995, A 202(1-2), p. 172-178.

[37] Panwar, N. and A. Chauhan, Fabrication methods of particulate reinforced Aluminium metal matrix composite-A review, Journal of Material Today Proceeding, 2018, 5(2), pp. 5933-5939.

[38] Bhingole, P., et al., Processing, microstructure and properties of ultrasonically processed in situ $\mathrm{MgO}-\mathrm{Al} 2 \mathrm{O} 3-\mathrm{MgAl} 2 \mathrm{O} 4$ dispersed magnesium alloy composites, Composites Part A, Applied Science and Manufacturing, 2014, 66, p. 209-217.

[39] Tjong, S.C., Novel nanoparticle-reinforced metal matrix composites with enhanced mechanical properties, Journal of Advance Engineering Materials, 2007, 9(8), pp. 639-652.

[40] Zhu, H., R. Abbaschian, In-situ processing of NiAl-alumina composites by thermite reaction. Material Science \& Engineering, 2000, A 282(1-2), p. 1-7.

[41] Kacher, J., et al., Impact of in situ nanomechanics on physical metallurgy, MRS Bulletin, 2019, 44(6), p. 465-470.

[42] Miracle, D, Metal matrix composites-from science to technological significance, Journal of Composites Science and Technology, 2005, 65(15-16), p. 2526-2540.

[43] Barmouz, M., et al., Investigation of mechanical properties of $\mathrm{Cu} / \mathrm{SiC}$ composite fabricated by FSP, Effect of SiC particles' size and volume fraction, Material Science \& Engineering, 2011, A 528(3), p. 1740-1749.

[44] Ghosh, S.K., et al., Influence of size and volume fraction of SiC particulates on properties of ex-situ reinforced $\mathrm{Al}-4.5 \mathrm{Cu}-3 \mathrm{Mg}$ metal matrix composite prepared by direct metal laser sintering process, Material Science \& Engineering, 2010, A 527(18-19), p. 4694-4701.

[45] Maleki, A., et al., Synthesis of In-situ aluminum matrix composite using a new activated powder injection method, Metallurgical and Materials Transactions, 2008, A39(12), p. 3034.

[46] Srivatsan, T.S., et al., Processing techniques for particulate-reinforced metal aluminium matrix composites, Journal of Materials Science, 1991, 26(22), pp. 5965-5978.

[47] Youssef, Y. and M.A El-Sayed, Effect of reinforcement particle size and weight fraction on the mechanical properties of SiC particle reinforced Al metal matrix composites, International Review of Mechanical Engineering (I.RE.M.E.), 2016, 10(4), p. 261-265.

[48] Kumar, G.V., et al., Studies on Al6061-SiC and Al7075- $\mathrm{Al}_{2} \mathrm{O}_{3}$ metal matrix composites, Journal of Minerals and Materials Characterization and Engineering, 2010, 9(1), pp. 43-55.

[49] Wang, Z., et al., Fabrication and properties of the TiC reinforced high-strength steel matrix composite, International Journal of Refractory Metals and Hard Materials, 2016, 58, pp. 14-21.

[50] Akhtar, F, Microstructure evolution and wear properties of in situ synthesized TiB2 and TiC reinforced steel matrix composites, Journal of Alloys and Compounds, 2008, 459(1-2), pp. 491-497.

[51] Pandey, U., et al., Effect of TiC particles on the mechanical properties of aluminium alloy metal matrix composites (MMCs), Journal of Material Today Proceeding, 2017, 4(4), pp. 5452-5460. 
[52] Karabulut, Ş., H. Karakoç, and R. Çıtak, Influence of B4C particle reinforcement on mechanical and machining properties of Al6061/B4C composites, Composites Part. B Engineering, 2016, 101, pp. 87-98.

[53] Dhanashekar, M., et al., Mechanical and wear behaviour of aa6061/sic composites fabricated by powder metallurgy method, Journal of Material Today Proceeding, 2020, 21, pp. 1008-1012.

[54] Moghdam, A.D., In-situ synthesis of aluminum-titanium diboride metal matrix hybrid nanocomposite, Theses and Dissertations, Journal of The University of WisconsinMilwaukee, 2016, 1137.

[55] Rajesh, S., et al., Influence and Wear Characteristics of TiC Particle in Al6061 Metal Matrix Composites, International Journal of Applied Engineering Research, 2018, 13(9), pp. 6514-6517.

[56] Gopalakrishnan, S. and N. Murugan, Production and wear characterisation of AA 6061 matrix titanium carbide particulate reinforced composite by enhanced stir casting method, Composites Part. B Engineering, 2012, 43(2), pp. 302-308.

[57] Kumar, K.R., et al., Micro structural characteristics and mechanical behaviour of aluminium matrix composites reinforced with titanium carbide, Journal of Alloys and Compounds, 2017, 723, pp. 795-801.

[58] Thevenot, F, Boron carbide - a comprehensive review, Journal of the European Ceramic society, 1990, 6(4), pp. 205-225.

[59] Toptan, F., A. Kilicarslan, and I. Kerti. The effect of Ti addition on the properties of Al-B4C interface, a microstructural study, Materials Science Forum, Trans Tech Publ., 2010.

[60] Patidar, D. and R. Rana, Effect of B4C particle reinforcement on the various properties of aluminium matrix composites, a survey paper, Journal of Material Today Proceeding, 2017, 4(2), pp. 2981-2988.

[61] Liu, S., et al., Effect of B4C and MOS2 reinforcement on micro structure and wear properties of aluminum hybrid composite for automotive applications, Composites Part. B Engineering 2019, 176, p. 107329.

[62] Ravi, B., B.B. Naik, and J.U. Prakash, Characterization of aluminium matrix composites (AA6061/B4C) fabricated by stir casting technique, Journal of Material Today Proceeding, 2015, 2(4-5), pp. 2984-2990.

[63] Manjunatha, B., et al., Effect of mechanical and thermal loading on boron carbide particles reinforced Al-6061 alloy, Material Science \& Engineering, 2015, A 632, pp. 147-155.

[64] Pilania, G., et al., Revisiting the $\mathrm{Al}_{\mathrm{Al}} \mathrm{O}_{2} \mathrm{O}_{3}$ interface, Coherent interfaces and misfit accommodation, Scientific reports, 2014, 4(1), pp. 1-9.

[65] Hima Gireesh, C., K. Durga Prasad, and K. Ramji, Experimental investigation on mechanical properties of an Al6061 hybrid metal matrix composite, Journal of Composites Science, 2018, 2(3), p. 49.

[66] Kandpal, B.C. and H. Singh, Fabrication and characterisation of Al2O3/aluminium alloy 6061 composites fabricated by Stir casting, Journal of Material Today Proceeding, 2017, 4(2), pp. 2783-2792.

[67] Mochane, M., et al., Recent progress on natural fiber hybrid composites for advanced applications, A review, The Council for Scientific and Industrial Research, 2019.

[68] Mihu, G., et al., Specific Heat and Thermal Expansion Coefficient of Hybrid Epoxy Composites, Materiale Plastice, 2020, 57(3), pp. 61-69.

[69] Amirkhanlou, S., S. Ji, A review on high stiffness aluminum-based composites and bimetallics, Critical Reviews in Solid State and Materials Sciences, 2020, 45(1), pp. 1-21. 
[70] Baburaja, K., K. Venkatasubbaiah, and R. Kalluri, ScienceDirect, Journal of Material Today Proceeding, 2016, 3, pp. 4140-4145.

[71] Ravindran, S., et al., Mechanical Behaviour of Aluminium Hybrid Metal Matrix CompositesA Review, Journal of Material Today Proceeding, 2019, 16, pp. 1020-1033.

[72] Kumar, N. and G. Irfan, Mechanical, microstructural properties and wear characteristics of hybrid aluminium matrix nano composites (HAMNCs)-review, Journal of Material Today Proceeding, 2020, 45, doi: 10.1016/j.matpr.2020.02.719.

[73] Jeyasimman, D., et al., An investigation of the synthesis, consolidation and mechanical behaviour of Al 6061 nanocomposites reinforced by TiC via mechanical alloying, Materials \& Design, 2014, 57, pp. 394-404.

[74] Muley, A.V., S. Aravindan, and I.J.M.R. Singh, Nano and hybrid aluminum based metal matrix composites, an overview, Manufacturing Review, 2015, 2, p. 15.

[75] Zhou, D., et al., Manufacture of nano-sized particle-reinforced metal matrix composites, a review, Acta Metallurgica Sinica (English Letters), 2014, 27(5), pp. 798-805.

[76] Sozhamannan, G., et al., Effect of applied load on the wear performance Of 6061 Al/Nano Ticp/Gr hybrid composites, Journal of Material Today Proceeding, 2018, 5(2), pp. 6489-6496.

[77] Pitchayyapillai, G., et al., Effect of nano-silver on microstructure, mechanical and tribological properties of cast 6061 aluminum alloy, Transactions of Nonferrous Metals Society of China, 2017, 27(10), pp. 2137-2145.

[78] Nagaral, M., et al., mechanical behaviour of aluminium 6061 alloy reinforced with al2o3 \& graphite particulate hybrid metal matrix composites. International Journal of Research in Engineering \& Technology (IJRET), 2013, 1(2), pp. 193-198.

Received: November 15, 2021

Accepted: December 14, 2021 